\title{
Quantitative Trait Loci Associated with Gray Leaf Spot Resistance in St. Augustinegrass
}

\author{
Xingwang Yu, ${ }^{1, \dagger}$ Steve E. Mulkey, ${ }^{2}$ Maria C. Zuleta, ${ }^{1}$ Consuelo Arellano, ${ }^{3}$ Bangya Ma, ${ }^{4}$ and Susana R. Milla-Lewis ${ }^{1}$ \\ ${ }^{1}$ Department of Crop and Soil Sciences, North Carolina State University, Raleigh, NC 27695, U.S.A. \\ ${ }^{2}$ Department of Agronomy and Plant Genetics, University of Minnesota, St. Paul, MN 55455, U.S.A. \\ ${ }^{3}$ Department of Statistics, North Carolina State University, Raleigh, NC 27695, U.S.A. \\ ${ }^{4}$ SePRO Research \& Technology Campus, Whitakers, NC 27891, U.S.A.
}

\begin{abstract}
Gray leaf spot (GLS), caused by Magnaporthe grisea, is a major fungal disease of St. Augustinegrass (Stenotaphrum secundatum), causing widespread blighting of the foliage under warm, humid conditions. To identify quantitative trait loci (QTL) controlling GLS resistance, an $F_{1}$ mapping population consisting of 153 hybrids was developed from crosses between cultivar Raleigh (susceptible parent) and plant introduction PI 410353 (resistant parent). Single-nucleotide polymorphism (SNP) markers generated from genotyping-by-sequencing constituted nine linkage groups for each parental linkage map. The Raleigh map consisted of 2,257 SNP markers and spanned 916.63 centimorgans (cM), while the PI 410353 map comprised 511 SNP markers and covered $804.27 \mathrm{cM}$. GLS resistance

lesion expansion curve, were calculated for QTL analysis. Twenty QTL were identified as being associated with these GLS resistance traits, which explained 7.6 to $37.2 \%$ of the total phenotypic variation. Three potential GLS QTL "hotspots" were identified on two linkage groups: P2 (106.26 to $110.36 \mathrm{cM}$ and 113.15 to $116.67 \mathrm{cM})$ and P5 $(17.74$ to $19.28 \mathrm{cM})$. The two major effect QTL $g l s p 2.3$ and glsp5.2 together reduced $20.2 \%$ of disease incidence in this study. Sequence analysis showed that two candidate genes encoding $\beta$-1,3-glucanases were found in the intervals of two QTL, which might function in GLS resistance response. These QTL and linked markers can be potentially used to assist the transfer of GLS resistance genes to elite St. Augustinegrass breeding lines.
\end{abstract} was evaluated under controlled environmental conditions with measurements of final disease incidence and lesion length. Additionally, two derived traits, area under the disease progress curve and area under the
Keywords: gray leaf spot, Magnaporthe grisea, quantitative trait loci, St. Augustinegrass
St. Augustinegrass (Stenotaphrum secundatum (Walt.) Kuntze) is a warm-season turfgrass adapted to the tropical and subtropical climates found in the southeastern United States. The broad leaf type and rapid stoloniferous growth of St. Augustinegrass that enable it to effectively outcompete weeds (Busey 2003; Long and Bashaw 1961) and its high tolerance to a wide range of soil types and shade (Busey 1995; Peacock and Dudeck 1993) make it a versatile option for home lawns and commercial landscapes. Previous work in St. Augustinegrass has primarily focused on phenotypic evaluation and classification within the species (Atilano and Busey 1983; Busey 1986; Flor et al. 2010). More recently, progress has been made in identifying variation within the germplasm at the genomic level (Milla-Lewis et al. 2013). Development of new cultivars has largely focused on the incorporation of abiotic and biotic stress tolerance and resistance traits into elite varieties that become more resilient to environmental stresses such as drought ( $\mathrm{Yu}$ et al. 2019) and cold (Kimball et al. 2018) or resistance to pests such as chinch bugs (Busey 1990). Breeding targets have also included growth type (Riordan et al. 1980) and turf quality (Yu et al. 2018). Despite these efforts,

${ }^{\dagger}$ Corresponding author: X. Yu; xyu15@ncsu.edu

Funding: This research was supported, in part, by the Center for Turfgrass Environmental Research and Education at North Carolina State University and by the United States Department of Agriculture National Institute of Food and Agriculture Specialty Crop Research Initiative grant 2015-51181-24291.

*The $\boldsymbol{e}$-Xtra logo stands for "electronic extra" and indicates that one supplementary figure is published online.

The author(s) declare no conflict of interest.

Accepted for publication 26 May 2020.

(C) 2020 The American Phytopathological Society
St. Augustinegrass remains susceptible to a number of pests and diseases, including gray leaf spot (GLS; causal agent: Magnaporthe grisea (T. T. Hebert) M. E. Barr), which cause significant damage to the turf stand.

GLS is a common disease throughout the grass family. The pathogen causes blast disease in rice, wheat, and barley, as well as GLS in tall fescue, ryegrass, and St. Augustinegrass. Control of GLS in most crops largely relies on the use of fungicides, making the management of this disease costly and difficult for most home lawn and public use settings. Alternatively, host genetic resistance would present an ideal approach for long term management of GLS. Recently, sources of resistance to GLS have been identified within St. Augustinegrass germplasm in our study (Carbajal 2017). Breeders hope to incorporate this resistance into elite varieties, which could be aided by a set of molecular markers linked to resistance genes or quantitative trait loci (QTL) through marker-assisted selection (MAS).

Because of its widespread prevalence in important food crops, rice has been widely researched as a model for host-pathogen interactions (Liu et al. 2010). Consequently, more than 100 blast resistance genes have been identified in this species (Srivastava et al. 2017). In addition to these single genes, which typically confer complete but race-specific resistance, QTL conferring partial resistance have also been identified in rice (Fukuoka and Okuno 2001; Xu et al. 2008), ryegrass (Curley et al. 2005), and barley (Sato et al. 2001). QTL are commonly associated with durable modes of resistance (Boyd 2006; Kou and Wang 2010) and present an ideal alternative to reliance upon fungicide for control of the disease. Active breeding efforts in rice have managed to produce varieties with durable resistance (Skamnioti and Gurr 2009; Wang et al. 1994), and provide proof of concept for application within St. Augustinegrass.

Linkage mapping provides an important foundation for QTL mapping and the identification of linked markers that can be used in breeding for resistance. Linkage maps have been used in rice (Zenbayashi et al. 2002), barley (Sato et al. 2001), and ryegrass 
(Curley et al. 2005) to identify resistance-linked markers for M. grisea. However, genomic information for turfgrass species remains limited. High-throughput sequencing technologies provide new tools for developing large numbers of single-nucleotide polymorphism (SNP) markers, exploring species diversity, constructing linkage maps, and performing genome-wide association studies (Huang et al. 2014). Recently, genotyping-by-sequencing (GBS) has been widely used to identify SNP markers in turfgrass species, including zoysiagrass (Holloway et al. 2018) and seashore paspalum (Qi et al. 2019), as well as St. Augustinegrass (Yu et al. 2018), which provides a powerful tool for SNP marker identification and QTL mapping. Therefore, the goals of this study were to (i) construct and evaluate a pseudo- $\mathrm{F}_{2}$ mapping population for resistance to GLS, (ii) characterize this population using SNP markers in order to construct linkage maps, and (iii) identify makers linked to QTL conferring resistance to the disease.

\section{Materials and Methods}

Mapping population. In total, $153 \mathrm{~F}_{1}$ hybrids were derived from the cross of commercial cultivar Raleigh and PI 410353, diploid ( $2 n=2 x=18)$ genotypes previously identified as being highly susceptible and resistant, respectively, to GLS (Carbajal 2017). Crosses were performed from maternal parent Raleigh and male parent PI 410353 following the procedures described by Genovesi et al. (2009). The population was maintained at the North Carolina State University Phytotron (Raleigh, NC, U.S.A.). Each individual was propagated vegetatively in plastic containers filled with Fafard potting mix (Conrad Fafard Inc., Agawam, MA, U.S.A.).

GLS disease evaluation. The experiment was conducted following a randomized complete block design. For a single replication, the 153 hybrids along with the parents were planted in plastic pots ( 5 by 5 by $7 \mathrm{~cm}$ ), randomly distributed in 10 plastic trays ( 25 by 35 by $3 \mathrm{~cm}$ ). The day prior to inoculation, total leaf numbers for each pot were counted in order to obtain a baseline for the calculation of disease incidence. Five pathogen isolates collected from the Lake Wheeler Turfgrass Field Laboratory (Raleigh, NC, U.S.A.) were selected and mixed for inoculation. To initiate the production of conidia, isolates were transferred to an oatmeal ryegrass agar for 20 to 25 days prior to harvesting. For conidial suspension preparation, $5 \mathrm{ml}$ of water was added to five healthy petri dishes of each isolate and spores were scraped free with a brush. Conidial suspensions of each isolate were filtered through cheesecloth and pooled together. Subsequently, the suspension's spore concentration was measured using a hemocytometer. This solution was then diluted to a concentration of $2 \times 10^{5}$ conidia/ml. Then, inoculations were performed by applying conidial suspension evenly over all blades of grass within a pot using an airbrush.

After inoculation, trays were filled with just enough water to cover the bottom and wrapped with a plastic cover to maintain $100 \%$ humidity and maintained at $30^{\circ} \mathrm{C}$ for the duration of the experiment. The plants were held in darkness for the first $48 \mathrm{~h}$ following inoculation, after which a 12 -h photoperiod was initiated. Measurements were made daily for 3 to 10 days after inoculation. Disease incidence (DI) was calculated from the number of infected leaves divided by the total number of leaves per pot, and mean lesion length (LL) was calculated based on the length of five randomly selected lesions per pot. Additionally, two derived parameters, area under the disease progress curve (AUDPC) and area under the lesion expansion curve (AULEC), were calculated from daily DI and LL values following da Silva et al. (2012). The final values of DI and LL were collected at the 10th day, as long as AUDPC and AULEC were used for QTL mapping. The experiment was conducted in three separate runs in November 2016 (E1), February 2017 (E2), and November 2017 (E3), with three replicates in each run.

Statistical analysis. Analysis of variance was performed using the SAS PROC GLM procedure (SAS Institute, Cary, NC, U.S.A.) with replication as random effect. Correlation analysis between traits and runs was performed using the SAS PROC CORR procedure
(SAS Institute). Least square means (LSmean) were calculated using the SAS PROC GLM procedure to obtain the average value over the three replicates for each line for each run. These LSmean values were used for QTL analysis in each single experiment run (E1, E2, or E3). In addition, QTL were identified across runs (combined from E1, E2, and E3) using "estimated" best linear unbiased predications (BLUP) of the set of genotypes evaluated. BLUP values were determined using R package lme 4 (Bates et al. 2007) following the model $Y_{i j k}=\mu+E_{i}+R(E)_{j i}+G_{k}+G E_{k i}+\varepsilon$, where $E_{i}=$ effect of experiment run $i, R(E)_{j i}=$ effect of replicate $j$ within run $i, G_{k}=$ effect of genotype $k, G E_{k i}=$ effect of interaction between genotype $k$ and $\operatorname{run} i$, and $\varepsilon=$ effect of error. All terms were considered as random except for the overall mean $(\mu)$.

Genotyping and map construction. Young leaves of each hybrid along with the parents were collected for genomic DNA extraction. The quality of the DNA was first visualized by agarose gel electrophoresis and further tested using NanoPhotometer (Implen, München, Germany). DNA concentration was quantified using a Hoefer DQ 300 fluorometer (Hoefer, Holliston, MA, U.S.A.). A GBS library containing genomic DNA of parents and hybrids was prepared according to the procedure detailed by Poland et al. (2012). The library was size selected at a range of 250 to $400 \mathrm{bp}$ using a D1000 ScreenTape assay (Agilent, Waldbronn, Germany) and sequenced on an Illumina HiSeq 2500 (Illumina, San Diego, CA, U.S.A.) at the North Carolina State University Genomic Sciences Laboratory (Raleigh, NC, U.S.A.). A GBS-SNP-CROP pipeline (v.4.0) was used to perform SNP discovery and genotyping (Melo et al. 2016). GBS raw reads were processed to keep only reads that contained barcodes and the restriction site. Reads from both parental lines were used to assemble the mock reference. To filter SNPs and call genotypes, several read depth and allele frequency-based parameters were used as follows: mnHoDepth $0=5$, mnHoDepth $1=20$, mnHetDepth $=3$, altStrength $=0.96$, mnAlleleRatio $=0.25$, mnAvgDepth $=4$, and mxAvgDepth $=200$. Finally, SNPs with less than $90 \%$ genotype calls were discarded.

JoinMap 4.0 was used to construct the linkage maps (Van Ooijen 2006). SNP markers that were heterozygous in parent Raleigh and homozygous in parent PI 410353 ( $1 \mathrm{~m} \times 11$ type) or homozygous in parent Raleigh and heterozygous in parent PI 410353 (nn $\times$ np type) were used to build the Raleigh and PI linkage maps, respectively. Both $1 \mathrm{~m} \times 11$ and $n n \times n p$ type markers showed a normal segregation ratio at 1:1. Markers that showed abnormal segregation ratios $\left(\chi^{2}\right.$ test, $\mathrm{df}=2$, cut-off value $\left.=9.21, P<0.01\right)$ were excluded from map construction. All linkage maps were constructed using the regression mapping algorithm, with a minimum logarithm of odds (LOD) of 9.0 and a maximum recombination rate of 0.4 (goodness-of-fit jump value 3.0 and ripple value 1). Map distances were calculated using the Kosambi mapping function. Map quality was checked with the N.N. fit function in JoinMap 4.0. MapChart 2.32 was used to visualize the linkage maps (Voorrips 2002).

QTL analysis. QTL analysis was performed using the integrated two-way pseudo-testcross approach with MapQTL 6.0 (Van Ooijen 2009). This approach was applied by analyzing data for each parental meiosis separately. Kruskal-Wallis analysis, interval mapping, and multiple QTL method analysis were performed to detect significant associations between markers and phenotypic traits using a regression approach. Genome-wide LOD thresholds $(P<$ $0.05)$ were determined for each trait using a permutation test with 10,000 iterations. Regions with an LOD score above threshold values were considered as potential QTL intervals.

Finally, sequences flanking SNP markers that fell within the identified regions of interest were searched against the NCBI NR database using blastn/blastp tools to obtain their orthologs. Gene annotation was conducted using the UniProt database to predict gene function in the QTL regions.

\section{Results}

Evaluation of GLS resistance. Four GLS-related traits (DI, LL, AUDPC, and AULEC) were evaluated to determine GLS resistance 
among members of the St. Augustinegrass mapping population. GLS severity of the resistant genotype PI 410353 was lower than the susceptible cultivar Raleigh in each evaluated trait under each evaluation run (Table 1; Supplementary Fig. S1). In all three runs, each trait related to GLS response displayed continuous variance in the population and appeared to be quantitative traits (Table 1; Supplementary Fig. S1). Genotype and run effects were significant $(P<0.001)$ for all traits, while genotype-run effects were only detected for DI and AUDPC (Table 1). The frequency distribution of all traits showed approximately normal distribution, and transgressive segregation was detected in each run (Supplementary Fig. S1). Correlations between traits were significant $(P<$ $0.0001)$ within each run, and a strong correlation between experiment runs was also found for each trait (Tables 2 and 3). Because AUDPC and AULEC were derived from DI and LL, respectively, the strongest correlations were observed in pairs AUDPC/DI and AULEC/LL (Table 2).

Construction of genetic maps. The map of parent Raleigh contained 2,257 SNP markers across nine linkage groups, named $\mathrm{R} 1$ to R9, which were ordered according to a previous linkage map (Yu et al. 2018). The map covered 916.63 centimorgans (cM), with an average distance between adjunct markers of 0.41 . The number of makers in each group ranged from 220 (R1) to 283 (R9) (Table 4; Fig. 1). The PI 410353 map harbored 511 makers, which were assigned into nine linkage groups ( $\mathrm{P} 1$ to P9). Through alignment with the genome of Setaria italica, which showed high similarity with St. Augustinegrass (Yu et al. 2018), linkage groups P2 to P5 and P7 to P9 were homologous with corresponding linkage groups in the Raleigh map, while both P1 and P6 were homologous with R1. The PI 410353 map spanned $804.27 \mathrm{cM}$, with an average marker distance of $1.57 \mathrm{cM}$. The number of markers per linkage group ranged from 5 (P1 and P6) to 94 (P2) (Table 4, Fig. 1).

QTL analysis. Putative QTL for GLS-related traits were detected on nine linkage groups (R5, R8, R9, P2, P3, P4, P5, P8, and P9) (Fig. 1; Table 5). For AUDPC, eight QTL for single run and BLUP were distributed on R5, P2, P3, P5, P8, and P9, with the highest explained variance of $37.2 \%$ ( $g l s p 2.3$ ). Among the five putative QTL detected for AULEC under single run and BLUP, glsp4.1 had the highest phenotypic variance explained of $17.4 \%$. For DI, eight putative QTL were detected on R8, R9, P2, P5, and P9 under single run and BLUP, from which glsp5.2 was repeatedly detected in E1, E2, and BLUP. This QTL explained $24.7 \%$ of the phenotypic variance. For LL, six putative QTL for single run and BLUP were found on R9, P2, P3, and P5, and they explained from 8.5 to $20.8 \%$ of the phenotypic variance ( $\mathrm{glsp} 2.5)$ (Table 5).

There were two "hotspot" regions on P2 and P5 that harbored multiple putative QTL, which were detected in more than one experimental run or for more than one trait (Table 5; Figs. 2 and 3). On group P2, glsp2.3 (105.66 to $110.36 \mathrm{cM})$, glsp2.4 (113.15 to $113.89 \mathrm{cM})$, and glsp2.5 (113.96 to $116.67 \mathrm{cM})$ were detected for AULEC, DI, and LL on BLUP and AUDPC, DI, and LL on E3 (Fig. 2). On group P5, QTL glsp5.1 (13.99 to $16.4 \mathrm{cM}$ ) and glsp5.2 (17.74 to $19.28 \mathrm{cM}$ ) were detected for AUDPC, AULEC, and DI on BLUP; DI on E1 and E2; and AUDPC on E2 (Fig. 3).

Allele effects of QTL and candidate GLS resistance genes. Two major-effect QTL, $g l s p 2.3$ and $g l s p 5.2$, that separately explained 37.2 and $19.4 \%$, respectively, of the phenotypic variance, were found in hotspot regions of the P2 and P5 groups. The nearest markers to them were GLS_1871 and GLS_1696. To further study the genetic effects of these QTL, the phenotypic variance was dissected for each QTL separately and in combination (Table 6). Progeny containing the two homozygous alleles in GLS_1696 and GLS_1871 (-/-) had a mean DI of 17.78, which served as a baseline for calculating GLS resistance in other allele combinations. With a single heterozygous allele in $g l s p 5.2(+/-)$, disease incidence was reduced by $4.8 \%$

Table 3. Pearson correlation coefficients among three independent experiment runs for disease incidence (DI), lesion length (LL), area under the disease progress curve (AUDPC), and area under the lesion expansion curve (AULEC) in a Raleigh $\times$ PI 410353 St. Augustinegrass mapping population evaluated for gray leaf spot response under controlled environmental conditions $^{\mathrm{a}}$

\begin{tabular}{|c|c|c|c|c|c|c|c|c|}
\hline \multirow[b]{2}{*}{ Experiment run } & \multicolumn{2}{|c|}{ AUDPC } & \multicolumn{2}{|c|}{ AULEC } & \multicolumn{2}{|c|}{ DI } & \multicolumn{2}{|c|}{$\mathbf{L L}$} \\
\hline & E1 & $\overline{\mathrm{E} 2}$ & E1 & E2 & E1 & $\overline{\mathrm{E} 2}$ & $\overline{\text { E1 }}$ & E2 \\
\hline $\mathrm{E} 2$ & 0.64 & . & 0.47 & $\ldots$ & 0.70 & $\ldots$ & 0.39 & \\
\hline E3 & 0.51 & 0.57 & 0.46 & 0.51 & 0.44 & 0.47 & 0.31 & 0.31 \\
\hline
\end{tabular}

a All correlations are significant at $P<0.0001$.

Table 1. Phenotypic value and variance analysis of disease incidence (DI), lesion length (LL), area under the disease progress curve (AUDPC), and area under the lesion expansion curve (AULEC) for a Raleigh $\times$ PI 410353 St. Augustinegrass mapping population evaluated for gray leaf spot response under controlled environmental conditions in three experimental runs $(\mathrm{E} 1 \text { to } \mathrm{E} 3)^{\mathrm{a}}$

\begin{tabular}{|c|c|c|c|c|c|c|c|c|c|}
\hline \multirow[b]{3}{*}{ Trait } & \multicolumn{2}{|c|}{ E1 } & \multicolumn{2}{|c|}{ E2 } & \multicolumn{2}{|r|}{$\mathbf{E 3}$} & \multirow{2}{*}{\multicolumn{3}{|c|}{ Effects $^{\mathbf{b}}$}} \\
\hline & Parents & Hybrids mean & Parents & Hybrids mean & Parents & Hybrids mean & & & \\
\hline & Raleigh/PI & (range) & Raleigh/PI & (range) & Raleigh/PI & (range) & G & $\mathbf{E}$ & $\mathbf{G} \times \mathbf{E}$ \\
\hline AUDPC & $49.5 / 25.2$ & $34.5(8.6-164.1)$ & $56.5 / 33.0$ & $42.5(5.8-299.1)$ & $85.5 / 46.3$ & $66.2(21.3-161.7)$ & $* * *$ & $* * *$ & $* * *$ \\
\hline AULEC & $22.0 / 12.8$ & $17.3(8.7-35.8)$ & $13.6 / 10.2$ & $12.4(6.6-22.9)$ & $11.1 / 6.9$ & $10.2(3.9-29.2)$ & $* * *$ & $* * *$ & NS \\
\hline DI $(\%)$ & $15.1 / 7.3$ & $10.4(2.1-35.0)$ & $17.8 / 9.8$ & $13.3(2.6-81.1)$ & $31.3 / 13.8$ & $24.6(6.3-46.9)$ & $* * *$ & $* * *$ & $* * *$ \\
\hline $\mathrm{LL}(\mathrm{mm})$ & $4.6 / 3.1$ & $3.8(2.1-6.8)$ & $3.7 / 2.4$ & $3.2(1.5-6.3)$ & $6.3 / 3.7$ & $5.7(2.8-10.2)$ & $* * *$ & $* * *$ & NS \\
\hline
\end{tabular}

${ }^{\mathrm{a}} \mathrm{PI}=$ parent line PI 410353.

${ }^{\mathrm{b}} \mathrm{G}=$ genotype, $\mathrm{E}=$ experimental run, asterisks $(* * *)$ indicate significance at $P$ value $<0.001$, and $\mathrm{NS}=$ not significant.

Table 2. Pearson correlation coefficients between disease incidence (DI), lesion length (LL), area under the disease progress curve (AUDPC), and area under the lesion expansion curve (AULEC) in a Raleigh $\times$ PI 410353 St. Augustinegrass mapping population evaluated for gray leaf spot response under controlled environmental conditions in three experimental runs (E1 to E3) ${ }^{\mathrm{a}}$

\begin{tabular}{|c|c|c|c|c|c|c|c|c|c|}
\hline \multirow[b]{2}{*}{ Trait } & \multicolumn{3}{|c|}{ E1 } & \multicolumn{3}{|c|}{ E2 } & \multicolumn{3}{|c|}{$\mathbf{E 3}$} \\
\hline & AUDPC & AULEC & $\overline{D I}$ & AUDPC & AULEC & $\overline{D I}$ & AUDPC & AULEC & DI \\
\hline AULEC & 0.64 & $\ldots$ & $\ldots$ & 0.61 & $\ldots$ & $\ldots$ & 0.69 & $\ldots$ & $\ldots$ \\
\hline DI & 0.93 & 0.64 & $\ldots$ & 0.98 & 0.62 & $\ldots$ & 0.79 & 0.59 & $\ldots$ \\
\hline LL & 0.59 & 0.88 & 0.62 & 0.55 & 0.84 & 0.59 & 0.61 & 0.69 & 0.56 \\
\hline
\end{tabular}

a All correlations are significant at $P<0.0001$. 
Table 4. Linkage group (LG) assignment, number of markers, LG size, and average distance between markers in linkage maps derived from the Raleigh $\times$ PI 410353 St. Augustinegrass population

\begin{tabular}{lrcc}
\hline Map, LG & $\begin{array}{c}\text { Number of } \\
\text { markers }\end{array}$ & Size $(\mathbf{c M})$ & Average distance \\
\hline Raleigh & & & \\
R1 & 220 & 96.45 & 0.44 \\
R2 & 254 & 131.84 & 0.52 \\
R3 & 276 & 93.76 & 0.34 \\
R4 & 261 & 91.07 & 0.35 \\
R5 & 225 & 122.06 & 0.54 \\
R6 & 258 & 74.11 & 0.29 \\
R7 & 244 & 82.52 & 0.34 \\
R8 & 236 & 103.6 & 0.44 \\
R9 & 283 & 121.23 & 0.43 \\
Total & 2,257 & 916.63 & 0.41 \\
PI 410353 & & & \\
P1 & 5 & 39.15 & 7.83 \\
P2 & 94 & 126.98 & 1.35 \\
P3 & 56 & 131.43 & 2.35 \\
P4 & 75 & 79.7 & 1.06 \\
P5 & 63 & 65.40 & 1.04 \\
P6 & 5 & 16.13 & 3.23 \\
P7 & 62 & 108.33 & 1.75 \\
P8 & 63 & 101.78 & 1.62 \\
P9 & 88 & 135.37 & 1.54 \\
Total & 511 & 804.27 & 1.57 \\
\hline
\end{tabular}

whereas, with a single heterozygous allele in $g l s p 2.3(-/+)$, disease incidence was reduced by $21.1 \%$. With the combination of two heterozygous alleles in both QTL $(+/+)$, disease incidence was reduced by $21.2 \%$ (Table 6 ).

In addition, flanking sequences of markers within the QTL interval were subsequently used to search for candidate resistance genes. Two genes (XM_025948638.1 and XM_004968938.4) encoding B-1,3glucanases, which are known as pathogenesis-related (PR) proteins, were found in both glsp2.3 and glsp5.2 from the genomes of Panicum hallii and S. italica.

\section{Discussion}

St. Augustinegrass can be severely affected by GLS disease, especially in climates favoring high temperature and humidity. Compared with fungicide treatments and other management strategies, developing and utilizing resistant cultivars is the preferred, sustainable approach for disease control because of its environmental sustainability. However, it takes several years to release a new diseaseresistant cultivar using phenotype-based conventional breeding methods. MAS would aid in speeding up that process by allowing rapid identification of resistant genotypes and transfer of favorable alleles into elite cultivars. In this study, we evaluated a segregating population for GLS resistance aimed to identify QTL controlling such damaging disease resistance in St. Augustinegrass. Due to the outcrossing nature and high level of heterozygosity in St. Augustinegrass, the $F_{1}$ population was segregating genetically in a way similar to that of the backcross population of selfpollinating species. Hence, only the loci with the homozygous genotype in one parent and heterozygous in the other parent were considered. In total, 2,257 SNP markers were identified in

\section{'Raleigh' map}
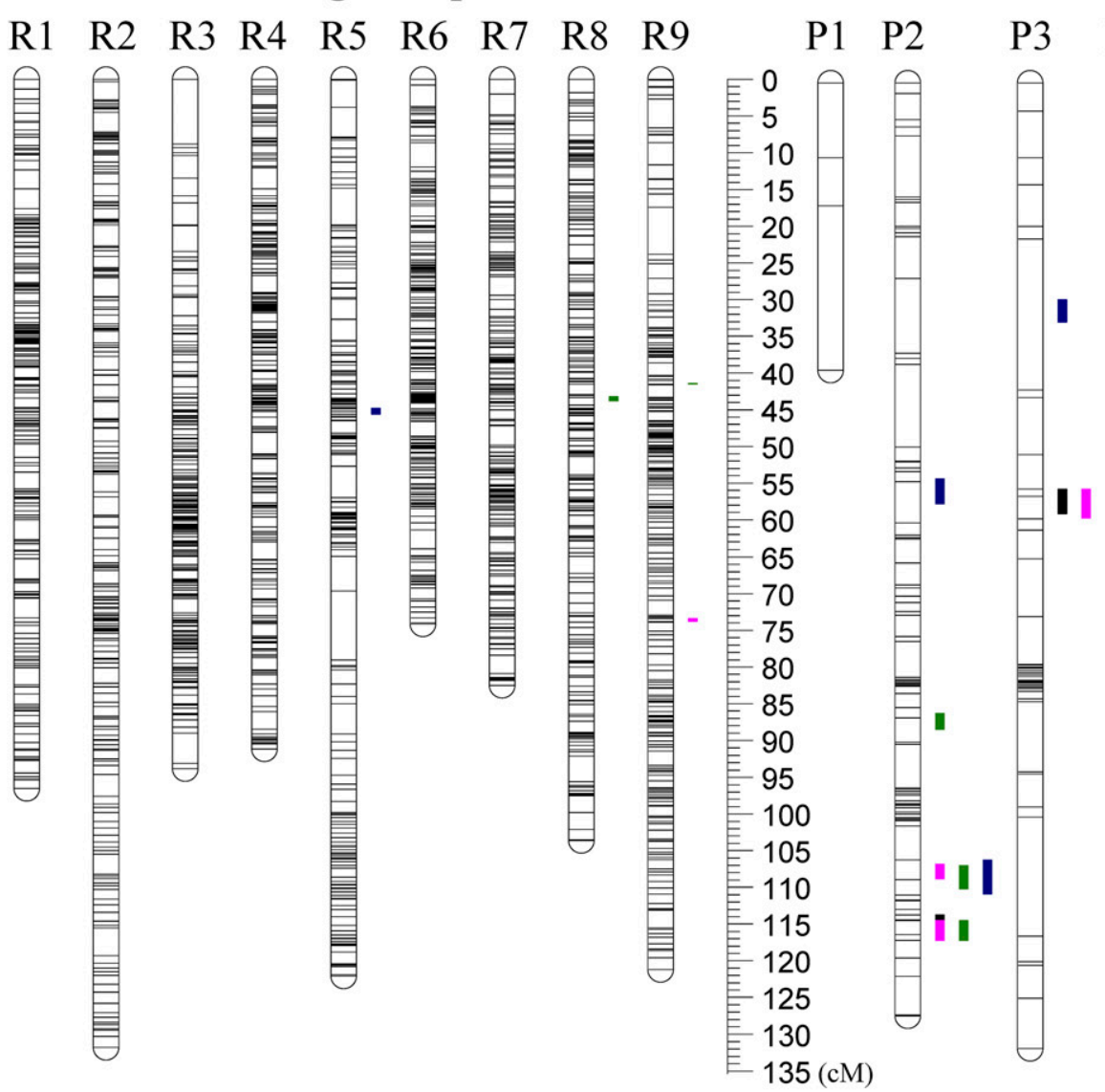

'PI410353' map
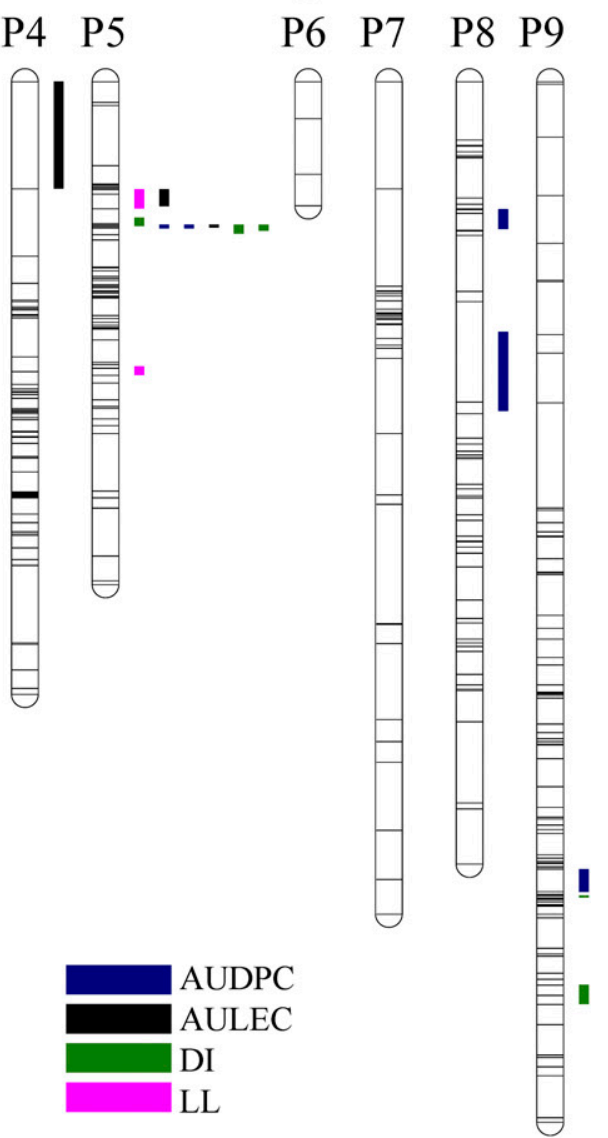

Fig. 1. Distribution of putative quantitative trait loci (QTL) identified for gray leaf spot resistance on two parental maps of St. Augustinegrass Raleigh $\times$ PI 410353 population. R1 to $\mathrm{R} 9=$ linkage groups of Raleigh map, $\mathrm{P} 1$ to $\mathrm{P9}=$ linkage groups of $\mathrm{PI} 410353$ map, $\mathrm{DI}=$ disease incidence, $\mathrm{LL}=$ lesion length, $\mathrm{AUDPC}=$ area under the disease progress curve, and $A U L E C=$ area under the lesion expansion curve. 
susceptible cultivar Raleigh, while only 511 SNP markers were found in resistant genotype PI 410353 (Table 4). Because these SNP markers were identified as being heterozygous in the corresponding parent genotype and homozygous in the other parent's genotype, it is obvious that there are more heterozygous loci in the genome of Raleigh. This indicates that the commercial cultivar Raleigh possesses higher heterozygosity than PI 410353. Cultivar Raleigh was collected from a home lawn in Raleigh, NC in 1964 , and was released for its superior cold tolerance in the early 1980s (Bateman 1980), while PI 410353 was collected from KwaZulu-Natal, South Africa in 1976 (https://npgsweb.ars-grin. gov/gringlobal/accessiondetail.aspx?id=1309370). Hence, the significant genetic diversity among the parent lines might be due to possible different evolutionary events from geographic isolation.

High-density linkage maps constructed from identified SNP markers in two parent lines provided platforms for QTL mapping. One of the main challenges in studying QTL mapping for disease resistance has been the lack of reliable methods to precisely characterize phenotypes. In the most universal approach, disease severity is rated using a 1-to-5 scale, based on a single observation, generally taken at the peak of disease progression. In the presence of quantitative or partial resistance in plants, disease development usually progresses slowly after infection. Hence, the effect of disease progression over time, including number of lesions and lesion expansion which can cause large differences between genotypes, should not be disregarded for QTL mapping. To address these issues, in addition to the final disease rating using DI and leaf LL, criteria AUDPC and AULEC were also used in the present study to determine disease progress 3 to 10 days after inoculation (da Silva et al. 2012; Tredway et al. 2003). AUDPC has been successfully used in the evaluation of quantitative resistance to stripe rust in barley (Yan and Chen 2008) and southern leaf blight in maize (Carson et al. 2004). In the present study, we adopted and optimized the evaluation approaches, and calculated AUDPC and AULEC from DI and LL of each day, which reflect the disease progress after infection. All of the evaluated criteria showed significant correlation between each other. Most importantly, several QTL exclusively associated with AUDPC and AULEC were detected in addition to those that overlapped with QTL for DI and LL, which enabled us to identify more loci controlling the GLS response. All of these results indicated the robustness and reliability of this approach for disease evaluation and for use in selecting lines possessing resistance to GLS in St. Augustinegrass.

Although more than 100 resistant genes have been identified for rice leaf blast (Srivastava et al. 2017), which is also caused by the same pathogen as GLS ( $M$. grisea), QTL and gene mapping for other grass species have lagged far behind. Curley et al. (2005) reported four QTL for GLS resistance from an Italian $\times$ perennial ryegrass population. Recently, a major-effect QTL

Table 5. Quantitative trait loci (QTL) found to have association with gray leaf spot traits identified in a Raleigh $\times$ PI 410353 St. Augustinegrass population from three experimental runs (E1 to E3) ${ }^{\mathrm{a}}$

\begin{tabular}{|c|c|c|c|c|c|c|c|c|c|c|}
\hline Trait, run & QTL & LG & Pos (cM) & Interval (cM) & Nearest marker & LOD & $\operatorname{Var}(\%)$ & Additive & $K$ test & Sig $K^{\prime} W^{b}$ \\
\hline \multicolumn{11}{|l|}{$\overline{\text { AUDPC }}$} \\
\hline BLUP & glsp5.2 & P5 & 18.83 & $18.64-18.98$ & GLS_1696 & 6.95 & 7.6 & -30.88 & 21.35 & $* * * * * *$ \\
\hline BLUP & glsr5.1 & R5 & 45.56 & $44.81-45.62$ & GLS_2432 & 9.8 & 10.3 & -50.87 & 8.9 & $* * * *$ \\
\hline E1 & glsp 9.1 & P9 & 104.54 & $102.54-105.39$ & GLS_4116 & 5.89 & 16.2 & 8.56 & 22.45 & $* * * * * * *$ \\
\hline E2 & glsp 2.1 & $\mathrm{P} 2$ & 54.31 & $53.85-57.31$ & GLS_3547 & 5.56 & 9.4 & 33.07 & 6.6 & $* *$ \\
\hline E2 & glsp3.1 & P3 & 30.28 & $29.48-32.56$ & GLS_3238 & 5.61 & 9.5 & -37.42 & 22.55 & $* * * * * * *$ \\
\hline E2 & glsp5.2 & P5 & 18.83 & $18.64-18.98$ & GLS_1696 & 12.74 & 19.4 & -70.54 & 19.93 & $* * * * * * *$ \\
\hline E2 & glsp8.1 & P8 & 16.58 & $16.58-19.09$ & GLS_2020 & 7.5 & 14.8 & -21.92 & 13.1 & $* * * * * *$ \\
\hline E2 & glsp 8.2 & P8 & 40.63 & $32.63-42.75$ & GLS_2400 & 6.99 & 14.2 & 19.86 & 11.31 & $* * * * *$ \\
\hline E3 & glsp2.3 & $\mathrm{P} 2$ & 108.36 & $105.66-110.36$ & GLS_1871 & 15.75 & 37.2 & -20.92 & 26.56 & $* * * * * * *$ \\
\hline \multicolumn{11}{|l|}{ AULEC } \\
\hline BLUP & glsp5.2 & P5 & 18.83 & $18.64-18.93$ & GLS_1696 & 3.85 & 10.9 & 0.91 & 16.49 & $* * * * * * *$ \\
\hline E1 & glsp5.1 & P5 & 14.9 & $13.99-16.1$ & GLS_4034 & 3.99 & 11.2 & 1.48 & 13.25 & $* * * * * *$ \\
\hline E3 & glsp2.4 & $\mathrm{P} 2$ & 113.89 & $113.15-113.89$ & GLS_3106 & 5.98 & 14.1 & -1.19 & 38.56 & $* * * * * * *$ \\
\hline E3 & glsp3.2 & P3 & 56.32 & $55.26-58.72$ & GLS_2751 & 4.14 & 9.5 & 0.97 & 27.19 & $* * * * * * *$ \\
\hline E2 & glsp 4.1 & $\mathrm{P} 4$ & 6.8 & $0-13.8$ & GLS_3251 & 6.37 & 17.4 & 1.22 & 25.38 & $* * * * * * *$ \\
\hline \multicolumn{11}{|l|}{ DI } \\
\hline BLUP & glsp 2.2 & $\mathrm{P} 2$ & 86.73 & $85.84-88.03$ & GLS_2560 & 7.66 & 15 & 3.61 & 5.02 & $* *$ \\
\hline BLUP & glsp 2.5 & $\mathrm{P} 2$ & 115.76 & $113.96-116.67$ & GLS_2808 & 11.8 & 24.7 & -4.08 & 26.66 & $* * * * * * *$ \\
\hline BLUP & glsp5.2 & $\mathrm{P} 5$ & 18.98 & $18.64-19.28$ & GLS_2276 & 5.3 & 8.6 & -8.72 & 19.72 & $* * * * * * *$ \\
\hline E1 & glsp 5.2 & P5 & 18.24 & $17.74-18.74$ & GLS_4638 & 6.2 & 8.8 & 8.71 & 25 & $* * * * * * *$ \\
\hline E2 & glsp5.2 & P5 & 18.83 & $18.63-19.68$ & GLS_1696 & 8.04 & 15 & -17.02 & 17.11 & $* * * * * * *$ \\
\hline E2 & glsp 9.3 & P9 & 119.41 & $117.64-120.01$ & GLS_3391 & 3.46 & 7.6 & 3.03 & 37.16 & $* * * * * * *$ \\
\hline E2 & glsr8.1 & R8 & 43.51 & $43.20-43.81$ & GLS_884 & 5.01 & 9.8 & -9.89 & 5.78 & $* *$ \\
\hline E2 & glsr 9.1 & R9 & 41.47 & $41.37-41.47$ & GLS_249 & 5.19 & 10.1 & -11.07 & 14.71 & $* * * * * *$ \\
\hline E3 & glsp2.3 & $\mathrm{P} 2$ & 108.16 & $106.46-109.66$ & GLS_1871 & 5.09 & 12.2 & -2.8 & 27.95 & $* * * * * * *$ \\
\hline E3 & glsp 9.2 & P9 & 106.12 & $105.85-106.12$ & GLS_2703 & 4.14 & 9.8 & 2.4 & 20.35 & $* * * * * * *$ \\
\hline \multicolumn{11}{|l|}{ LL } \\
\hline BLUP & glsp2.3 & $\mathrm{P} 2$ & 107.56 & $106.26-108.26$ & GLS_1871 & 4.5 & 8.5 & -0.26 & 34.36 & $* * * * * * *$ \\
\hline BLUP & glsp3.2 & P3 & 56.92 & $55.26-59.32$ & GLS_2751 & 5.11 & 9.7 & 0.28 & 25.67 & $* * * * * * *$ \\
\hline E1 & glsp5.1 & P5 & 14.6 & $13.99-16.4$ & GLS_4034 & 5.2 & 14.5 & 0.32 & 21.05 & $* * * * * * *$ \\
\hline E2 & glsp5.3 & P5 & 37.3 & $37.1-38.1$ & GLS_2456 & 4.24 & 10.6 & 0.24 & 18.75 & $* * * * * * *$ \\
\hline E2 & glsr 9.2 & R9 & 73.64 & $73.44-73.81$ & GLS_2012 & 3.86 & 9.6 & -0.24 & 13.59 & $* * * * * *$ \\
\hline E3 & glsp 2.5 & $\mathrm{P} 2$ & 115.26 & $113.96-116.67$ & GLS_2808 & 7.68 & 20.8 & -0.6 & 34.17 & $* * * * * * *$ \\
\hline
\end{tabular}

${ }^{a} \mathrm{LG}=$ linkage group, Pos = peak position, $\mathrm{LOD}=$ logarithm of odds, Var = explained variance, Sig. KW = significance by Kruskal-Wallis analysis, AUDPC = area under the disease progress curve, BLUP = best linear unbiased predication, AULEC $=$ area under the lesion expansion curve, DI = disease incidence, and $\mathrm{LL}=$ lesion length

b Significance levels of KW analysis: $*=0.1, * *=0.05, * * *=0.01, * * * *=0.005, * * * * *=0.001, * * * * * *=0.0005$, and $* * * * * * *=0.0001$. 
explaining 61.0 to $69.5 \%$ GLS resistance variance was identified on LG3 of an $F_{1}$ population in Italian ryegrass (Takahashi et al. 2014). In this study, QTL analysis was performed using highdensity genetic maps and phenotypic evaluation of GLS resistance under controlled environmental conditions. For the first time in a warm-season turfgrass species, 20 QTL conferring GLS resistance were identified in St. Augustinegrass (Table 5). The putative QTL showed segregation of alleles at multiple loci, each with a moderate effect, suggesting that quantitative genetic resistance for GLS exists in St. Augustinegrass. This type of resistance could prove to be more durable because it is harder for pathogens to adapt to and overcome it (Corwin and Kliebenstein 2017). Moreover, two hotspot regions were found on linkage groups $\mathrm{P} 2$ and $\mathrm{P} 5$ of the resistant parent, and two major-effect QTL, glsp2.3 and $g l s p 5.2$, were identified. These QTL could be repeatedly detected for different traits and on experimental runs, which increases their value as candidates for diagnostic makers. Most importantly, the combination of these two QTL could improve $20.2 \%$ of DI compared with progeny with two susceptible alleles (Table 6), indicating that transferring these positive alleles into St. Augustinegrass cultivars through MAS could effectively improve GLS resistance. However, due to the lack of availability of genomic information for St. Augustinegrass, limited gene information could be accessible in the interval of these QTL. The molecular mechanisms of GLS resistance in St. Augustinegrass remain unclear.

By alignment with close grass species ( $P$. hallii and $S$. italica), two PR genes encoding $\beta$-1,3-glucanases were found in the two major-effect
QTL separately. Plant $\beta$-1,3-glucanases are directly involved in defense by hydrolyzing the cell walls of fungal pathogens. The protein could also be involved in signal cascades of plant defense response (Balasubramanian et al. 2012). The $\beta$-1,3-glucanases sourced from a wide range of species, including alfalfa, tomato, soybean, tobacco, and wheat, play key roles in diverse types of disease resistance (Aggarwal et al. 2011; Dong et al. 2007; Maziah et al. 2007; Salim et al. 2011; Sridevi et al. 2008). Salim et al. (2011) reported that tomato early blight pathogen-resistant genotype LE996 showed an enhanced expression of $\beta$-1,3-glucanases $(71 \%)$ compared with susceptible genotype LE150. In wheat, a spot blotch pathogenresistant genotype showed a higher expression level of $\beta$-1,3-glucanases within $24 \mathrm{~h}$ after inoculation than the susceptible genotype (Aggarwal et al. 2011). The PR protein was also used to develop transgenic varieties resistant to pathogens. The alfalfa $\beta$-1,3-glucanase AGLU1 gene was introduced into turf-type tall fescue (Festuca arundinacea) through Agrobacterium-mediated transformation. The transgenic plants showed high levels of resistance to GLS (Dong et al. 2007). Therefore, we believe that the predicted PR protein genes could improve GLS resistance in St. Augustinegrass. In the future, we will investigate them to understand their potential roles in resistance to GLS.

\section{Acknowledgments}

We thank the staff at the North Carolina State University Phytotron for assistance in maintaining plant material, and L. Miranda from BASF and H. Zhang from the Donald Danforth Plant Science Center for manuscript review.

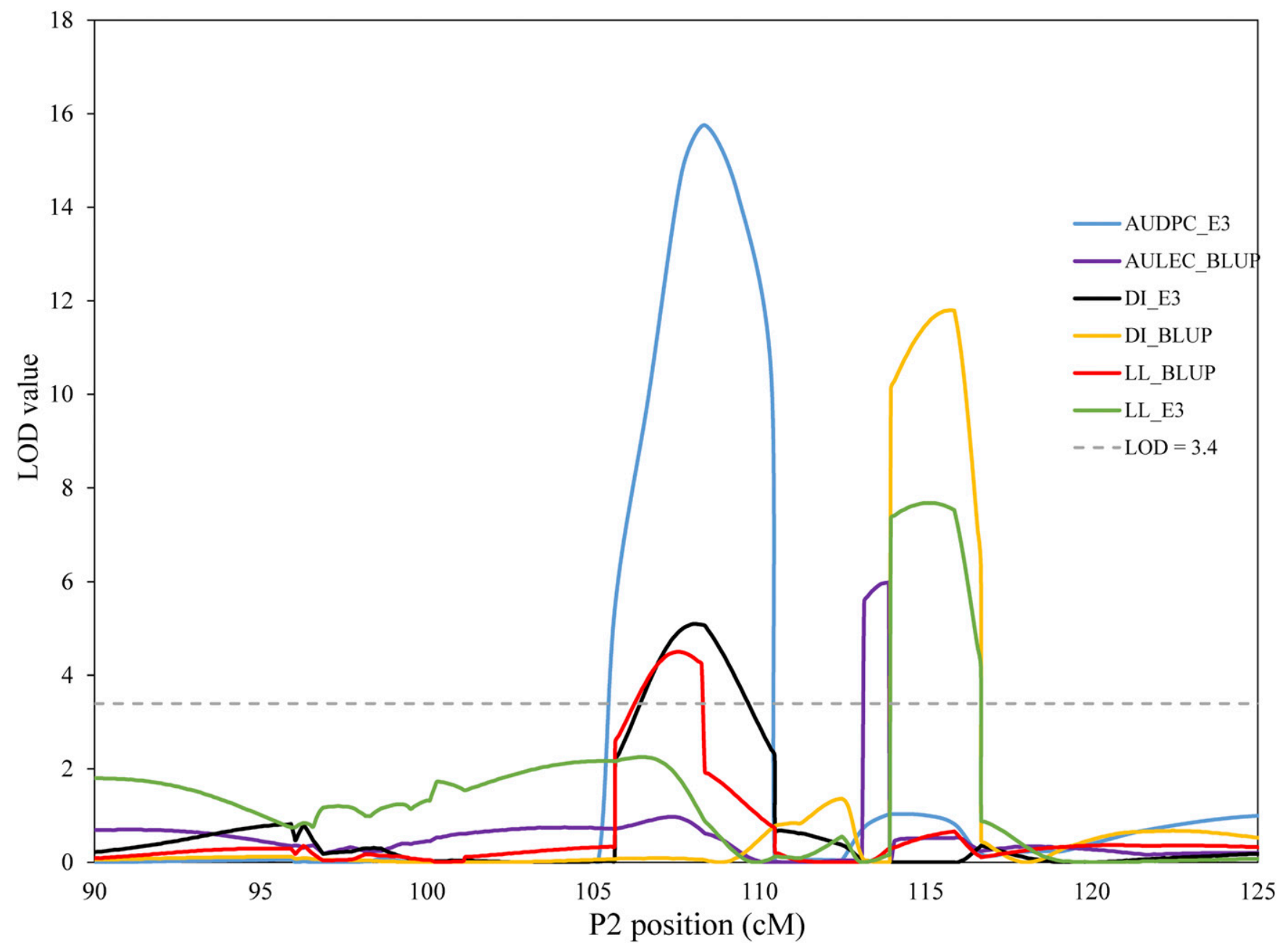

Fig. 2. Logarithm of odds (LOD) score of the quantitative trait loci (QTL) for gray leaf spot resistance in the linkage group P2 harboring colocalized QTL in St. Augustinegrass. DI = disease incidence, $\mathrm{LL}=$ lesion length, AUDPC = area under the disease progress curve, AULEC $=$ area under the lesion expansion curve, BLUP $=$ best linear unbiased predication, and $\mathrm{cM}=$ centimorgans. 


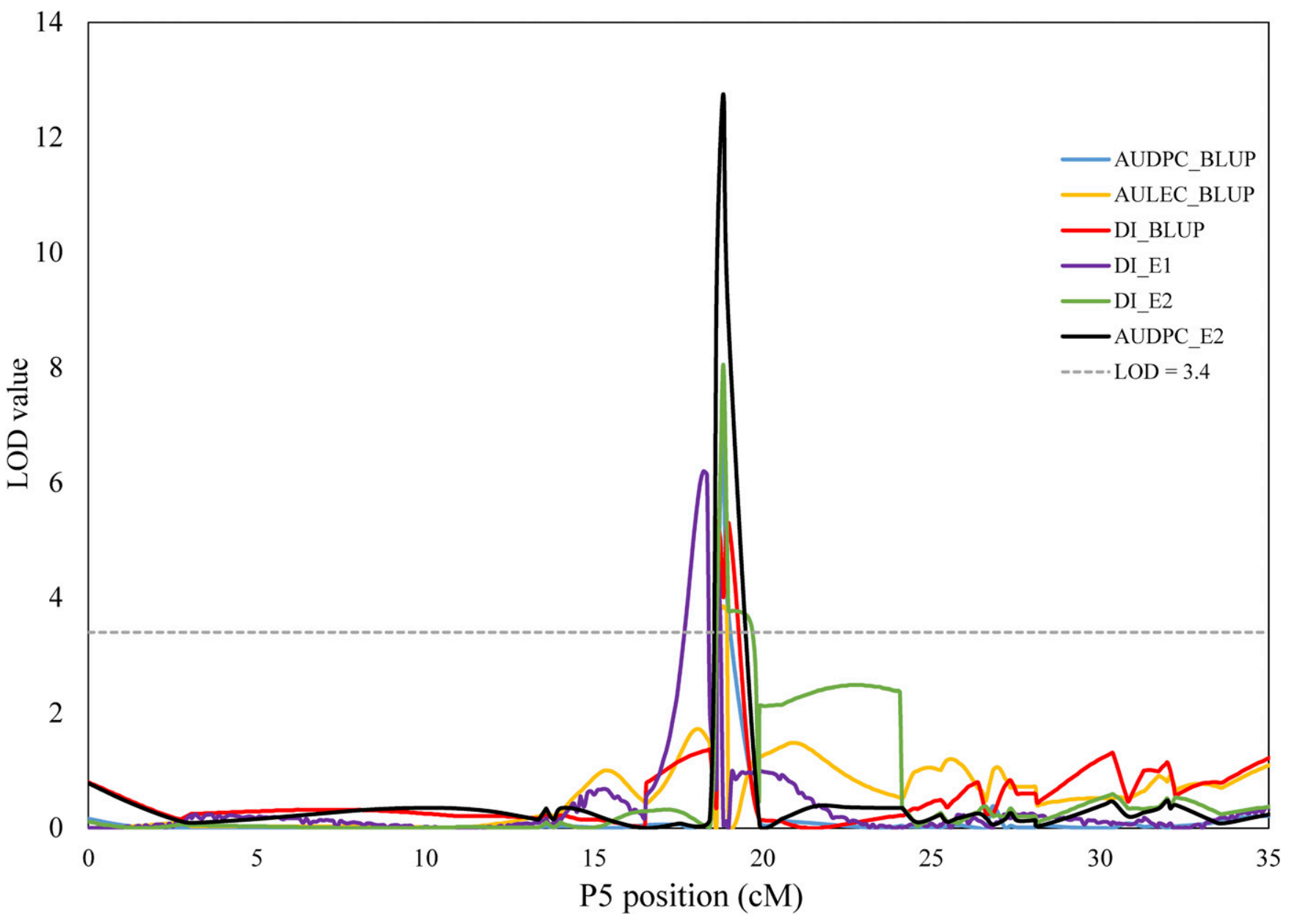

Fig. 3. Logarithm of odds (LOD) score of the quantitative trait loci (QTL) for gray leaf spot resistance in the linkage group P5 harboring colocalized QTL in St. Augustinegrass. DI = disease incidence, $\mathrm{AUDPC}=$ area under the disease progress curve, $\mathrm{AULEC}=$ area under the lesion expansion curve, BLUP $=$ best linear unbiased predication, and $\mathrm{cM}=$ centimorgans.

Table 6. Allele combination effects of major quantitative trait loci (QTL) on gray leaf spot disease incidence in the St. Augustinegrass Raleigh $\times$ PI 410353 population

\begin{tabular}{lcccc}
\hline QTL $\left(\right.$ glsp5.2/glsp2.3) $^{\mathbf{a}}$ & Genotypes $^{\mathbf{b}}$ & Disease incidence $^{\mathbf{c}}$ & Number of progeny & ${\text { Difference }(\%)^{\mathbf{d}}}^{\boldsymbol{P}_{\text {value }}}$ \\
\hline$-/-$ & $\mathrm{Ho} / \mathrm{Ho}$ & 17.78 & 57 & 0 \\
$+/-$ & $\mathrm{He} / \mathrm{Ho}$ & 16.93 & 34 & 4.8 \\
$-/+$ & $\mathrm{Ho} / \mathrm{He}$ & 14.04 & 19 & 21.1 \\
$+/+$ & $\mathrm{He} / \mathrm{He}$ & 14.02 & 42 & $<0.01$ \\
\hline
\end{tabular}

a Symbols + and - represent presence and absence, respectively, of corresponding QTL.

${ }^{\mathrm{b}}$ Genotypes of the nearest marker (GLS_1696/GLS_1871) for $g l s p 5.2 / g l s p 2.3$. Ho $=$ homozygous genotype and He $=$ heterozygous genotype

c Average best linear unbiased predication value of progeny across three experiment runs.

d Difference and $P$ value were obtained by comparison with Ho/Ho genotypes; NS = not significant.

\section{Literature Cited}

Aggarwal, R., Purwar, S., Kharbikar, L., and Gupta, S. 2011. Induction of a wheat $\beta$-1,3-glucanase gene during the defense response to Bipolaris sorokiniana. Acta Phytopathol. Entomol. Hung. 46:39-47.

Atilano, R. A., and Busey, P. 1983. Susceptibility of St. Augustinegrass germplasm to Pyricularia grisea. Plant Dis. 67:782-783.

Balasubramanian, V., Vashisht, D., Cletus, J., and Sakthivel, N. 2012. Plant $\beta$-1,3glucanases: Their biological functions and transgenic expression against phytopathogenic fungi. Biotechnol. Lett. 34:1983-1990.

Bateman, D. R. 1980. Notice to sod producers and growers relative to the naming and release of the new St. Augustine cultivar 'Raleigh. North Carolina Agricultural Research Service, Raleigh, NC, U.S.A.

Bates, D., Sarkar, D., Bates, M. D., and Matrix, L. 2007. The lme4 package. R package version 2, 74. http://btr0x2.rz.uni-bayreuth.de/math/statlib/R/CRAN/ doc/packages/lme4.pdf

Boyd, L. 2006. Can the durability of resistance be predicted? J. Sci. Food Agric. 86:2523-2526.

Busey, P. 1986. Morphological identification of St. Augustinegrass cultivars. Crop Sci. 26:28-32.
Busey, P. 1990. Polyploid Stenotaphrum germplasm: Resistance to the polyploid damaging population southern chinch bug. Crop Sci. 30:588-593.

Busey, P. 1995. Genetic diversity and vulnerability of St. Augustinegrass. Crop Sci. 35:322-327.

Busey, P. 2003. St. Augustinegrass, Stenotaphrum secundatum (Walt.) Kuntze. Pages 309-329 in: Turfgrass Biology, Genetics, and Breeding. M. D. Casler and R. R. Duncan, eds. John Wiley \& Sons, Hoboken, NJ, U.S.A.

Carbajal, E. M. 2017. Breeding for improved St. Augustinegrass through ploidy manipulation and identification of gray leaf spot-resistant germplasm. Master's Degree, North Carolina State University, Raleigh, NC, U.S.A.

Carson, M. L., Stuber, C. W., and Senior, M. L. 2004. Identification and mapping of quantitative trait loci conditioning resistance to southern leaf blight of maize caused by Cochliobolus heterostrophus race O. Phytopathology 94 : 862-867.

Corwin, J. A., and Kliebenstein, D. J. 2017. Quantitative resistance: More than just perception of a pathogen. Plant Cell 29:655-665.

Curley, J., Sim, S. C., Warnke, S., Leong, S., Barker, R., and Jung, G. 2005. QTL mapping of resistance to gray leaf spot in ryegrass. Theor. Appl. Genet. 111: $1107-1117$ 
da Silva, M. R., Martinelli, J. A., Federizzi, L. C., Chaves, M. S., and Pacheco, M. T. 2012. Lesion size as a criterion for screening oat genotypes for resistance to leaf spot. Eur. J. Plant Pathol. 134:315-327.

Dong, S., Tredway, L. P., Shew, H. D., Wang, G. L., Sivamani, E., and Qu, R. 2007. Resistance of transgenic tall fescue to two major fungal diseases. Plant Sci. 173:501-509.

Flor, N. C., Harmon, P. F., Datnoff, L. E., and Raid, R. N. 2010. Screening of St. Augustinegrass (Stenotaphrum secundatum) germplasm for brown patch and large patch resistance. (Abstr.) Phytopathology 100:S36.

Fukuoka, S., and Okuno, K. 2001. QTL analysis and mapping of pi21, a recessive gene for field resistance to rice blast in Japanese upland rice. Theor. Appl. Genet. 103:185-190.

Genovesi, A. D., Jessup, R. W., Engelke, M. C., and Burson, B. L. 2009. Interploid St. Augustinegrass [Stenotaphrum secundatum (Walt.) Kuntze] hybrids recovered by embryo rescue. In Vitro Cell. Dev. Biol. 45:659-666.

Holloway, H. M., Yu, X., Dunne, J. C., Schwartz, B. M., Patton, A. J., Arellano, C., and Milla-Lewis, S. R. 2018. A SNP- based high-density linkage map of zoysiagrass (Zoysia japonica Steud.) and its use for the identification of QTL associated with winter hardiness. Mol. Breed. 38:10.

Huang, Y. F., Poland, J. A., Wight, C. P., Jackson, E. W., and Tinker, N. A. 2014. Using genotyping-by-sequencing (GBS) for genomic discovery in cultivated oat. PLoS One 9:e102448.

Kimball, J. A., Tuong, T. D., Arellano, C. A., Livingston, D. P., III, and MillaLewis, S. R. 2018. Linkage analysis and the identification of quantitative trait loci associated with freeze tolerance and turf quality traits in St. Augustinegrass. Mol. Breed. 38:67.

Kou, Y., and Wang, S. 2010. Broad-spectrum and durability: Understanding of quantitative disease resistance. Curr. Opin. Plant Biol. 13:181-185.

Liu, J., Wang, X., Mitchell, T., Hu, Y., Liu, X., Dai, L., and Wang, G. L. 2010. Recent progress and understanding of the molecular mechanisms of the riceMagnaporthe oryzae interaction. Mol. Plant Pathol. 11:419-427.

Long, J. A., and Bashaw, E. C. 1961. Microsporogenesis and chromosome numbers in St. Augustinegrass. Crop Sci. 1:41-43.

Maziah, M., Saraih, M., and Sreeramanan, S. 2007. Transgenic banana rastali (AAB) with $\beta$-1,3-glucanase gene for tolerance to Fusarium wilt race 1 disease via Agrobacterium-mediated transformation system. Plant Pathol. J. 6:271-282.

Melo, A. T., Bartaula, R., and Hale, I. 2016. GBS-SNP-CROP: A reference-optional pipeline for SNP discovery and plant germplasm characterization using variable length, paired-end genotyping-by-sequencing data. BMC Bioinf. 17:29.

Milla-Lewis, S. R., Zuleta, M. C., Van Esbroeck, G. A., Quesenberry, K. H., and Kenworthy, K. E. 2013. Cytological and molecular characterization of genetic diversity in Stenotaphrum. Crop Sci. 53:296-308.

Peacock, C. H., and Dudeck, A. E. 1993. Response of St. Augustinegrass cultivars [Stenotaphrum secundatum (Walt.) Kuntze] to shade. Int. Turfgrass Soc. Res. J. 7:657-663.

Poland, J., Brown, P. J., Sorrells, M. E., and Jannink, J. 2012. Development of high-diversity genetic maps for barley and wheat using a novel two-enzyme genotyping by sequencing approach. PLoS One 7:e32253.

Qi, P., Eudy, D., Schnable, J. C., Schmutz, J., Raymer, P. L., and Devos, K. M. 2019. High density genetic maps of seashore paspalum using genotyping-bysequencing and their relationship to the Sorghum Bicolor genome. Sci. Rep. $9: 12183$.
Riordan, V., Meier, D., Long, J. A., and Gruis, J. T. 1980. Registration of Seville St. Augustinegrass. Crop Sci. 20:824-825.

Salim, A. P., Saminaidu, K., Marimuthu, M., Perumal, Y., Rethinasamy, V., Palanisami, J. R., and Vadivel, K. 2011. Defense responses in tomato landrace and wild genotypes to early blight pathogen Alternaria solaniinfection and accumulation of pathogenesis-related proteins. Arch. Phytopathol. Plant Prot. 44:1147-1164.

Sato, K., Inukai, T., and Hayes, P. M. 2001. QTL analysis of resistance to the rice blast pathogen in barley (Hordeum vulgare). Theor. Appl. Genet. 102:916-920.

Skamnioti, P., and Gurr, S. J. 2009. Against the grain: Safeguarding rice from rice blast disease. Trends Biotechnol. 27:141-150.

Sridevi, G., Parameswari, C., Sabapathi, N., Raghupathy, V., and Veluthambi, K. 2008. Combined expression of chitinase and $\beta$-1,3-glucanase genes in indica rice (Oryza sativa L.) enhances resistance against Rhizoctonia solani. Plant Sci. 175:283-290.

Srivastava, D., Shamim, M., Kumar, M., Mishra, A., Pandey, P., Kumar, D., Yadav, P., Siddiqui, M. H., and Singh, K. N. 2017. Current status of conventional and molecular interventions for blast resistance in rice. Rice Sci. 24:299-321.

Takahashi, W., Miura, Y., Sasaki, T., and Takamizo, T. 2014. Identification of a novel major locus for gray leaf spot resistance in Italian ryegrass (Lolium multiflorum Lam.). BMC Plant Biol. 14:303.

Tredway, L. P., Stevenson, K. L., and Burpee, L. L. 2003. Components of resistance to Magnaporthe grisea in 'Coyote' and 'Coronado' tall fescue. Plant Dis. 87:906-912.

Van Ooijen, J. W. 2006. JoinMap 4, Software for the Calculation of Genetic Linkage Maps in Experimental Populations. Kyazma BV, Wageningen, The Netherlands.

Van Ooijen, J. W. 2009. MapQTL 6: Software for the Mapping of Quantitative Trait Loci in Experimental Populations of Diploid Species. Kyazma BV, Wageningen, The Netherlands.

Voorrips, R. E. 2002. MapChart: Software for the graphical presentation of linkage maps and QTLs. J. Hered. 93:77-78.

Wang, G. L., Mackill, D. J., Bonman, J. M., McCouch, S. R., Champoux, M. C. and Nelson, R. J. 1994. RFLP mapping of genes conferring complete and partial resistance to blast in a durably resistant rice cultivar. Genetics 136: $1421-1434$

Xu, X., Chen, H., Fujimura, T., and Kawasaki, S. 2008. Fine mapping of a strong QTL of Weld resistance against rice blast, Pikahei-1(t), from upland rice Kahei, utilizing a novel resistance evaluation system in the greenhouse. Theor. Appl. Genet. 117:997-1008.

Yan, G., and Chen, X. 2008. Identification of a quantitative trait locus for hightemperature adult-plant resistance against Puccinia striiformis f. sp. hordei in 'Bancroft' barley. Phytopathology 98:120-127.

Yu, X., Brown, J. M., Graham, S. E., Carbajal, E. M., Zuleta, M. C., and MillaLewis, S. R. 2019. Detection of quantitative trait loci associated with drought tolerance in St. Augustinegrass. PLoS One 14:e0224620.

Yu, X., Kimball, J. A., and Milla-Lewis, S. R. 2018. High density genetic maps of St. Augustinegrass and applications to comparative genomic analysis and QTL mapping for turf quality traits. BMC Plant Biol. 18:346.

Zenbayashi, K., Ashizawa, T., Tani, T., and Koizumi, S. 2002. Mapping of the QTL (quantitative trait locus) conferring partial resistance to leaf blast in rice cultivar Chubu 32. Theor. Appl. Genet. 104:547-552. 